\title{
Effects of an Educational Intervention on Breast Self-Examination, Breast Cancer Prevention-Related Knowledge, and Healthy Lifestyles in Scholars from a Low-Income Area in Bogota, Colombia
}

\author{
A. M. Masso-Calderón ${ }^{1}$ - J. F. Meneses-Echávez ${ }^{1,2}$ • J. E. Correa-Bautista ${ }^{1}$. \\ A. Tovar-Cifuentes ${ }^{1}$ • P. A. Alba-Ramírez ${ }^{1}$ - C. E. Charry-Ángel ${ }^{1}$
}

Published online: 4 November 2016

(C) The Author(s) 2016. This article is published with open access at Springerlink.com

\begin{abstract}
The aim of this study was to evaluate the effects of an educational intervention on breast self-examination, cancer prevention-related knowledge, practices, and behavior change in scholars from a low-income area in Bogota, Colombia. Uncontrolled trial was conducted in 155 scholars. Two educational sessions, 90 min each, were carried out in March 2015 according to the Colombian guidelines for educational communication in the framework of cancer control. All participants completed a self-reported questionnaire at pre- and post-intervention, as well as 1,3 , and 6 months after the intervention. Breast self-examination was practiced by $78.1 \%$ of the scholars, and the overall knowledge of breast cancer risk factors was poor. The educational intervention resulted in significant improvements on breast self-examination practice, the knowledge of the technique, and the knowledge of the main risk factors for breast cancer as well as the practice of physical activity and vegetable intake at 6 months follow-up. An educational intervention according to the Colombian guidelines for educational communication in the framework of cancer control improved the practice of breast self-examination, cancer prevention-related knowledge, as well as the practice of physical activity and vegetable consumption in scholars from
\end{abstract}

J. F. Meneses-Echávez menesesjose77@gmail.com

1 Centro de Estudios en Medición de la Actividad Física (CEMA), Escuela de Medicina y Ciencias de la Salud, Universidad del Rosario, Bogotá, Colombia

2 Norwegian Knowledge Centre for the Health Services in the Norwegian Institute of Public Health, PO Box 4404, Nydalen, N-0403 Oslo, Norway a low-income area in Bogota, Colombia. Further randomized controlled studies are warranted.

Keywords Breast cancer $\cdot$ Risk factor $\cdot$ Prevention

\section{Introduction}

Breast cancer is a serious public health problem, which has been recognized as the most common cancer in women worldwide [1]. In Colombia, breast cancer represents the third leading cause of death [2]. Breast self-examination (BSE) is related to self-awareness and self-care habits, associated with the facilitation of cancer screening [3]. There is no evidence about the effects of BSE on early detection of breast cancer [4]. Different organizations recommend regular self-examination in women over 20 years old in the promotion of selfawareness and risk control [5]. Nevertheless, most of women remain unaware about the technique of breast examination and the main risk factors for breast malignancies, especially of those related to lifestyle [6-8], although most of women can recognize hereditary factor as the main importance [9].

There is strong evidence that healthy lifestyles prevent breast cancer, as well as other type of cancers [10]. Physical activity exerts its effects on breast cancer prevention by modulating inflammatory markers [11], insulin-related factors [12], and other biological mechanisms [13]. Recently, Colditz and Bohlke [14] have reported that healthy lifestyles can reduce nearly half of breast cancer incidence annually; the control of physical inactivity could reduce $10 \%$ of such incidence. In addition, physically active young women can achieve risk reductions of around $25 \%$, even more when active and healthy behaviors are adopted during youth and early adulthood [14]. As stated by McTiernan and colleagues, 
interventions that promote changes in lifestyle, including reduced alcohol consumption, reduced fat intake, and the practice of regular physical activity, can lower the risk of developing the disease and will have additional benefits by also lowering the risk of developing other noncommunicable diseases [15].

In light of this, educational interventions have been recommended as effective public actions in the integral control of breast cancer, especially among youth [16]. There is consistent evidence that educational interventions can improve both knowledge and practice of BSE in young women up to 6 and 12 months follow-up [17, 18]. Besides, educational interventions can also improve physical activity [19], as well as fruits and vegetable consumption in scholars [20,21].

In the Colombian context, there are scarce evidences about educational interventions for breast cancer prevention, whereas the benefits of the national guidelines for educational communication in the framework of cancer control reaming is unknown [22]. The current agenda for cancer control in Colombia emphasizes on the need of community-based research for both detection and prevention [23]. The aim of this study was to evaluate the effects of an educational intervention on BSE, cancer prevention-related knowledge, and healthy lifestyles in a group of female scholars from a low-income area in Bogota, Colombia.

\section{Methods}

\section{Design}

The study design was uncontrolled trial with repeated measurements at 1, 3, and 6 months post-intervention.

\section{Participants}

We selected a convenience sample of 155 female adolescents (10-20 years old), students of a public school in a low-income area in Bogota, Colombia. The purpose of study, interventions, and dates were explained in the classroom to the eligible students. Those who referred pregnancy, breastfeeding, or previous participation in a similar educational intervention were excluded.

\section{Ethics}

Ethical approval to conduct this study was obtained from the ethics committee of the Our Lady of the Rosary University (Reference N. 306), after approval of the research protocol. Written informed consent was taken for each participant. Parents provided signed consent for each minor.

\section{Data Collection}

\section{Knowledge of Breast Cancer Risk Factors}

We used the breast section of the Cancer Awareness Measure (CAM) [24, 25], which was developed and validated in 20072008 by the Cancer Research UK, the University College London, the King's College, and Oxford University. The following question was used: Do you think that each of these can increase the chance of getting breast cancer? Responses were measured using the nominal scale of "yes" and "no."

\section{Breast Self-Examination}

BSE practice and knowledge of the technique were measured using a validated questionnaire provided by the German multicentre DACH in the University of Düsseldorf, Germany [26]. For BSE, we asked the following: How often do you check your breasts? Responses were measured using the nominal scale of "yes" and "no."

\section{Healthy Lifestyle}

We adapted the Spanish version of the Behavioral Risk Factor Surveillance System published by the Centers for Disease Control and Prevention (CDC) [27]. The following domains were evaluated: smoking, alcohol consumption, physical activity (>150 $\mathrm{min} /$ week), and fruits and vegetable intake. Weekly use/consumption was measured using the nominal scale of "yes" and "no."

\section{Questionnaire Validity}

All modules were translated into Spanish by one researcher, and back translation was conducted and checked by one independent bilingual translator to ensure equivalence. The final version of the questionnaire was then piloted in a subgroup of 50 scholars who completed the tool and provided feedback regarding feasibility, clarity, and understanding. No lingual difficulties were identified.

The questionnaire was completed by all participants under supervision of the sports teacher, as suggested by the Cancer Research UK [25]. Cronbach's alpha was used to assess the internal consistency, and Pearson's correlation test was used to evaluate the test-retest reliability over a 7-day interval. Sensitivity to change is interpreted with the study results (i.e., changes scores).

\section{Educational Intervention}

The educational intervention was developed in accordance with the national guidelines for educational communication in the framework of cancer control in Colombia [22], 
incorporating the use of clear language, flexible and understandable vocabulary. In order to facilitate the adherence and completion, the intervention contents were articulated to the school curriculum. The two 90 min educational sessions were carried out in March 2015 emphasizing on the normal breast, BSE, breast cancer risk factors and symptoms, the role of healthy lifestyles on breast cancer prevention, and methods for screening and early detection (Table 1). One researcher and teacher supervised both sessions and procedures. The pedagogical resources were videos, presentations, and open discussions. The students prepared various posters and placed them on the most crowded areas of the school. At the end of the workshop, each participant received a copy of the educational content provided. Follow-up assessments were undertaken at 1, 3, and 6 months after the intervention.

\section{Statistical Analysis}

The outcome of interest was the BSE practice, knowledge of breast cancer risk factors, and healthy lifestyles. The sociodemographic characteristics of scholars were described by using frequency, percentage, mean, and standard deviation. A multilevel regression model was used to estimate the change coefficients in the different scores with respect to pre-intervention measurements; each measurement was then assumed as a hierarchical source of variability. Alpha levels of $p<0.05$ were considered as significant. The data were analyzed using the Stata version 22.0.

\section{Results}

\section{Questionnaire Performance and Reliability}

Cronbach's alpha provided scores over 0.7 for all items in the questionnaire, which suggested a strong level of internal consistency. Similarly, Pearson's correlation test showed strong test-retest reliability (over 0.72$)$ for all items $(p<0.05)$ over a 7-day interval.

\section{Sociodemographic Characteristics of Study Participants}

A total of 155 female scholars participated in the educational intervention and received the whole content. Their mean age was 13.72 years \pm 1.9 standard deviations (SD) (range 10-20). All scholars are residents in a low-income area in south Bogota, Colombia. Only half of the participants live with both parents, and less than half of the parents have completed academic studies (Table 2).
Table 1 Educational intervention for breast self-examination and breast cancer prevention

Educational intervention for breast self-examination and breast cancer prevention through healthy lifestyles: key components

Introduction to healthy lifestyles and cancer prevention

Review of the learning objectives

Normal breast (basic anatomy and physiology)

Breast self-examination

Breast cancer risk factors (i.e., modifiable and non-modifiable)

Symptoms of breast cancer

Early detection of breast cancer

Treatment options of breast cancer

\section{Effects of the Educational Intervention on BSE Knowledge, Practice, and Frequency}

Baseline scores showed poor levels for these outcomes. Knowledge of the BSE technique showed a significant exponential increase across all measurements $(p<0.0001)$. Eighty percent of the scholars had never examined their breasts, and this rate showed a significant decrease of $67.8 \%$ (from 80.7 to $12.9 \%)$ at 6 months $(p<0.0001)$. Similar increases were also found for the frequency of BSE in all the categories evaluated. See Table 3.

\section{Effects of the Educational Intervention on Knowledge of Breast Cancer Risk Factors}

Less than $10 \%$ of the participants recognized late-onset menopause, nulliparity, and the family history of cancer while only $37 \%$ of participants recognized sedentary behavior as a risk
Table 2 Sociodemographic characteristics of study participants

\begin{tabular}{lll}
\hline Characteristics & $\mathrm{n}$ & $(\%)$ \\
\hline Age (years) & & \\
$<15$ & 127 & $(81.9)$ \\
$>15$ & 28 & $(18.1)$ \\
Home composition & & \\
Both parents & 86 & $(55)$ \\
Only father & 11 & $(7.1)$ \\
Only mother & 32 & $(22.6)$ \\
Others & 23 & $(14.8)$ \\
Father's education & & \\
None & 30 & $(19.4)$ \\
High school & 73 & $(47.1)$ \\
University & 52 & $(33.5)$ \\
Mother's education & & \\
None & 10 & $(6.5)$ \\
High school & 78 & $(50.3)$ \\
University & 67 & $(43.2)$ \\
\hline
\end{tabular}


Table 3 Effects of the educational intervention on BSE knowledge, practice, and frequency

\begin{tabular}{|c|c|c|c|c|c|}
\hline Variable & $\begin{array}{l}\text { Pre* } \\
n(\%)\end{array}$ & $\begin{array}{l}\text { Post } \\
n(\%) \\
p \text { value }\end{array}$ & $\begin{array}{l}1 \text { month } \\
n(\%) \\
p \text { value }\end{array}$ & $\begin{array}{l}3 \text { months } \\
n(\%) \\
p \text { value }\end{array}$ & $\begin{array}{l}6 \text { months } \\
n(\%) \\
p \text { value }\end{array}$ \\
\hline \multirow[t]{2}{*}{ BSE practice } & \multirow[t]{2}{*}{$41(26.5 \%)$} & $49(5.1 \%)$ & $62(13 \%)$ & $61(12 \%)$ & $120(50 \%)$ \\
\hline & & 0.273 & $0.004 * *$ & $0.006^{* *}$ & $<0.0001 * *$ \\
\hline \multirow[t]{2}{*}{ Knowledge of BSE technique } & \multirow[t]{2}{*}{$42(27.1 \%)$} & $94(33 \%)$ & $102(38 \%)$ & $121(50 \%)$ & $130(56 \%)$ \\
\hline & & $<0.0001 * *$ & $<0.0001 * *$ & $<0.0001 * *$ & $<0.0001 * *$ \\
\hline \multicolumn{6}{|l|}{ BSE frequency** } \\
\hline Never & $125(80.7 \%)$ & $111(71.7 \%)$ & $100(64.5 \%)$ & $49(31.6 \%)$ & $20(12.9 \%)$ \\
\hline 1-2 times/year & $18(11.6 \%)$ & $14(9 \%)$ & $7(4.50 \%)$ & 0 & 0 \\
\hline 3-10 times/year & $9(5.8 \%)$ & $25(16.1 \%)$ & $38(24.5 \%)$ & $5(3.2 \%)$ & $14(9 \%)$ \\
\hline >10 times/year & $3(1.9 \%)$ & $5(3.2 \%)$ & $10(6.5 \%)$ & $101(65.2 \%)$ & $121(78.1 \%)$ \\
\hline
\end{tabular}

The percentages mean the score change with respect to pre-intervention values.

*Affirmative responses to each variable

**Statistically significant differences factor at pre-intervention. The scholars referred significant increases on knowledge of all risk factors up to 6 months after the intervention (Table 4).

\section{Effects of the Educational Intervention on Healthy Lifestyles for Breast Cancer Prevention}

The educational intervention decreased weekly alcohol consumption at 6 months after the intervention (11\% decrease). Significant improvements were observed on the practice of physical activity and vegetable consumption $(p<0.05)$. See Table 5.

\section{Discussion}

Our findings demonstrated an educational intervention improve the knowledge of BSE, its practice, the knowledge of the main risk factors for breast cancer, and healthy lifestyles in a group of female scholars up to 6 months follow-up.

\section{BSE Knowledge, Practice, and Frequency}

We observed large improvements on BSE knowledge, practice, and frequency at 6 months follow-up. These findings are in line with those of recent studies carried out in Malaysia [17], Turkey [28], and Iran [29]. Nevertheless, it is important to consider some age differences in terms of applicability. This uncontrolled trial led to a complete adoption of monthly examination in the scholars.

\section{Knowledge of Breast Cancer Risk Factors}

The knowledge of the Colombian female scholars was poor for most of the breast cancer risk factors and showed significant improvements after the educational intervention, which is similar to those reported in females from Malaysia [17], Iran [30], Egypt [31], and India [32]. These findings highlight the role of educational interventions in empowering young women in the battle against breast cancer.

\section{Healthy Lifestyles for Breast Cancer Prevention}

In spite of a lack of statistical significance on some domains, we can state that this educational intervention improved healthy lifestyles in the scholars.

Alcohol consumption exhibited a small reduction at 6 months follow-up. Similar promising findings have been reported by the Project Toward No Drug Abuse [33] and the Project Northland [34] in high school students from the USA. Contradictory results have been found in Norway in junior high school students with a mean age of 13.5 years [35]. Further research has been desired by the latest Cochrane review [36].

Scholars referred an unexpected small increase (1\%) in smoking at 6 months after the intervention. The Cochrane Tobacco Addiction Group has discussed similar results from 49 randomized controlled trials (over 140,000 school children) and concluded that prevention studies did not provide overall effect at 1 year or less, and multimodal interventions and those with an information-only approach were similarly ineffective [37]. However, a national level successful strategy "Ending the Tobacco Epidemic: A Tobacco Control Strategic Action Plan for the U.S. Department of Health and Human 
Table 4 Effects of the educational intervention on knowledge of breast cancer risk factors

\begin{tabular}{|c|c|c|c|c|c|}
\hline Breast cancer & Pre* & Post & 1 month & 3 month & 6 month \\
\hline \multirow[t]{2}{*}{ risk factors } & \multirow[t]{2}{*}{$n(\%)$} & $n(\%)$ & $n(\%)$ & $n(\%)$ & $n(\%)$ \\
\hline & & $p$ value & $p$ value & $p$ value & $p$ value \\
\hline \multirow[t]{2}{*}{ Age } & \multirow[t]{2}{*}{$89(57.4 \%)$} & $120(77.4 \%)$ & $127(81.9 \%)$ & $144(92.9 \%)$ & $145(93.5 \%)$ \\
\hline & & $(0.000)^{* *}$ & $(0.000)^{* *}$ & $(0.000)^{* *}$ & $(0.000)^{* *}$ \\
\hline \multirow[t]{2}{*}{ Early menarche } & \multirow[t]{2}{*}{$34(21.9 \%)$} & $94(60.6 \%)$ & $106(68.3 \%)$ & $132(85.1 \%)$ & $142(91.6 \%)$ \\
\hline & & $(0.006)^{* *}$ & $(0.000)^{* *}$ & $(0.000)^{* *}$ & $(0.000)^{* *}$ \\
\hline \multirow[t]{2}{*}{ Late pregnancy } & \multirow[t]{2}{*}{$33(21.3 \%)$} & $122(78.7 \%)$ & $123(79.3 \%)$ & $143(92.2 \%)$ & $148(95.4 \%)$ \\
\hline & & $(0.000)^{* *}$ & $(0.000)^{* *}$ & $(0.000)^{* *}$ & $(0.000)^{* *}$ \\
\hline \multirow[t]{2}{*}{ Previous tumors } & \multirow[t]{2}{*}{$67(43.2 \%)$} & $99(63.8 \%)$ & $117(75.4 \%)$ & $147(94.8 \%)$ & $151(97.4 \%)$ \\
\hline & & $(0.000)^{* *}$ & $(0.000)^{* *}$ & $(0.000)^{* *}$ & $(0.000)^{* *}$ \\
\hline \multirow[t]{2}{*}{ Family history of cancer } & \multirow[t]{2}{*}{$47(9.7 \%)$} & $77(49.6 \%)$ & $69(44.5 \%)$ & $110(70.9 \%)$ & $124(80 \%)$ \\
\hline & & $(0.104)$ & $(0.718)$ & $(0.000)^{* *}$ & $(0.000)^{* *}$ \\
\hline \multirow[t]{2}{*}{ Nulliparity } & \multirow[t]{2}{*}{$5(3.2 \%)$} & $104(67 \%)$ & $105(67.7 \%)$ & $138(89 \%)$ & $145(93.5 \%)$ \\
\hline & & $(0.000)^{* *}$ & $(0.000)^{* *}$ & $(0.000)^{* *}$ & $(0.000)^{* *}$ \\
\hline \multirow[t]{2}{*}{ Late-onset menopause } & \multirow[t]{2}{*}{$10(6.5 \%)$} & $101(65.1 \%)$ & $94(60.6 \%)$ & $129(83 \%)$ & $146(94.1 \%)$ \\
\hline & & $(0.000)^{* *}$ & $(0.000)^{* *}$ & $(0.000)^{* *}$ & $(0.000)^{* *}$ \\
\hline \multirow[t]{2}{*}{ No breastfeeding } & \multirow[t]{2}{*}{$36(23.2 \%)$} & $105(67.7)$ & $108(69.6 \%)$ & $135(87 \%)$ & $145(93.5 \%)$ \\
\hline & & $(0.000)^{* *}$ & $(0.000)^{* *}$ & $(0.000)^{* *}$ & $(0.000)^{* *}$ \\
\hline \multirow[t]{2}{*}{ Sedentarism } & \multirow[t]{2}{*}{$58(37.4 \%)$} & $123(79.3 \%)$ & $119(76.7 \%)$ & $118(76.1 \%)$ & $144(92.9 \%)$ \\
\hline & & $(0.000)^{* *}$ & $(0.000)^{* *}$ & $(0.000)^{* *}$ & $(0.000)^{* *}$ \\
\hline \multirow[t]{2}{*}{ Low intake of fruits and vegetables } & \multirow[t]{2}{*}{$34(21.9 \%)$} & $93(60 \%)$ & $76(49 \%)$ & $121(78 \%)$ & $142(91.6 \%)$ \\
\hline & & $(0.000)^{* *}$ & $(0.000)^{* *}$ & $(0.000)^{* *}$ & $(0.000)^{* *}$ \\
\hline \multirow[t]{2}{*}{ Sleep $<7$ h/day } & \multirow[t]{2}{*}{$15(9.7 \%)$} & $43(27.7 \%)$ & $53(34.1 \%)$ & $119(76.7 \%)$ & $144(92.9 \%)$ \\
\hline & & $(0.000)^{* *}$ & $(0.000)^{* *}$ & $(0.000)^{* *}$ & $(0.000)^{* *}$ \\
\hline \multirow[t]{2}{*}{ Contraceptive pills } & \multirow[t]{2}{*}{$71(45.8 \%)$} & $116(74.8 \%)$ & $104(67 \%)$ & $133(85.8 \%)$ & $144(92.9 \%)$ \\
\hline & & $(0.000)^{* *}$ & $(0.000)^{* *}$ & $(0.000)^{* *}$ & $(0.000)^{* *}$ \\
\hline
\end{tabular}

The percentages mean the score change with respect to pre-intervention values.

*Affirmative responses to each variable

**Statistically significant differences

Services", which combining all educational, clinical, regulatory, economic, and social initiatives, has shown decreases of up to $20 \%$ or more in some states [38].

We found exponential significant improvements in the practice of physical activity (>150 min/week) in the scholars. Similar findings have been communicated in a Cochrane review (44 studies involving 36,593 children and adolescents) which concluded that educational interventions combining printed educational materials and changes to the school curriculum that promote physical activity during school hours can lead to positive effects in increasing duration of physical activity from 5 to $45 \mathrm{~min}$ more per day and other outcomes such as the time spent watching television from 5 to $60 \mathrm{~min}$ less per day, and physical fitness [39]. Considering some context-related differences, we are able to recommend school-based interventions for the promotion of physically active behaviors aiming at noncommunicable disease prevention.
Our improvements in fruit and vegetable intake are similar to those published by Evans and colleagues [40] in 2012 summarizing evidence from 27 school-based programs involving 26,361 children, who reported increases of nearly 0.25 portions of fruit and vegetable daily intake. We did not evaluate the number of portions.

\section{Strengths and Weaknesses}

This study is the first evidence in evaluating the Colombian guidelines for educational communication in the framework of cancer control. It is important to highlight the relevance of involving low-income groups in educational interventions since these individuals have limited access to most of the massive educational campaigns that take place in the country [23]. However, the lack of a random assignment and a control group preclude the statement of stronger conclusions about the effects of our educational intervention. 
Table 5 Effects of the educational intervention on healthy lifestyles for breast cancer prevention

\begin{tabular}{|c|c|c|c|c|c|}
\hline $\begin{array}{l}\text { Domains of } \\
\text { lifestyle } \\
\text { (Weekly use) }\end{array}$ & $\begin{array}{l}\text { Pre* } \\
n(\%)\end{array}$ & $\begin{array}{l}\text { Post } \\
n(\%) \\
p \text { value }\end{array}$ & $\begin{array}{l}1 \text { month } \\
n(\%) \\
p \text { value }\end{array}$ & $\begin{array}{l}3 \text { months } \\
n(\%) \\
p \text { value }\end{array}$ & $\begin{array}{l}6 \text { months } \\
n(\%) \\
p \text { value }\end{array}$ \\
\hline Smoking & $6(3.8 \%)$ & $\begin{array}{l}7(4.5 \%) \\
(0.714)\end{array}$ & $\begin{array}{l}9(5.8 \%) \\
(0.271)\end{array}$ & $\begin{array}{l}9(5.8 \%) \\
(0.271)\end{array}$ & $\begin{array}{l}7(4.5 \%) \\
(0.714)\end{array}$ \\
\hline Alcohol consumption & $27(17.4 \%)$ & $\begin{array}{l}22 \\
(0.377)\end{array}$ & $\begin{array}{l}(14.1 \%) \\
(0.596)\end{array}$ & $\begin{array}{l}18(11.6 \%) \\
(0.112)\end{array}$ & $\begin{array}{l}18(11.6 \%) \\
(0.112)\end{array}$ \\
\hline Physical activity (>150 min/wk) & $44(28.3 \%)$ & $\begin{array}{l}49(31.6 \%) \\
(0.061)\end{array}$ & $\begin{array}{l}58(37.4 \%) \\
(0.000)\end{array}$ & $\begin{array}{l}105(67.7 \%) \\
(0.000)\end{array}$ & $\begin{array}{l}132(85.1 \%) \\
(0.000)\end{array}$ \\
\hline Fruit intake & $119(76.7 \%)$ & $\begin{array}{l}114(73.5 \%) \\
(0.060)\end{array}$ & $\begin{array}{l}114(73.5 \%) \\
(0.010)\end{array}$ & $\begin{array}{l}119(76.7 \%) \\
(0.196)\end{array}$ & $\begin{array}{l}118(76.1 \%) \\
(0.000)\end{array}$ \\
\hline Vegetable intake & $70(45.1 \%)$ & $\begin{array}{l}90(58 \%) \\
(0.001)\end{array}$ & $\begin{array}{l}68(43.8 \%) \\
(0.047)\end{array}$ & $\begin{array}{l}82(52.9 \%) \\
(0.029)\end{array}$ & $\begin{array}{l}127(81.9 \%) \\
(0.000)\end{array}$ \\
\hline
\end{tabular}

The percentages mean the score change with respect to pre-intervention values.

*Affirmative responses to each variable

**Statistically significant differences

\section{Implications for Research}

Further well-conducted randomized controlled trials can provide more rigorous evidence about the effects of educational interventions in improving female potential for breast cancer early detection and its prevention through healthy lifestyles. Further RCTs must incorporate strong sample sizes and adequate methods for allocation concealment, sequences generation, and outcome measurement. The use of objective measurements for lifestyle-related outcomes is also warranted.

\section{Implications for Practice}

The results from this study are articulated with the priorities of the cancer risk control and prevention strategies of the Colombian Ministry of Health [23] and those from other international authorities. We recommend a detailed analysis of the applicability of our study findings since most of the current evidence comes from high-income countries.

\section{Conclusion}

An educational intervention based on the Colombian guidelines for educational communication in the framework of cancer control improves BSE practice, breast cancer preventionrelated knowledge, as well as the practice of physical activity and vegetable consumption in scholars from a low-income area in Bogota, Colombia. Further randomized controlled studies are warranted.

\section{Compliance with Ethical Standards}

Conflict of Interest The authors declare no conflict of interest

Ethical approval to conduct this study was obtained from the ethics committee of the Our Lady of the Rosary University (Reference N. 306), after approval of the research protocol.

Open Access This article is distributed under the terms of the Creative Commons Attribution 4.0 International License (http:// creativecommons.org/licenses/by/4.0/), which permits unrestricted use, distribution, and reproduction in any medium, provided you give appropriate credit to the original author(s) and the source, provide a link to the Creative Commons license, and indicate if changes were made.

\section{References}

1. Ferlay J, Shin HR, Bray F, Forman D, Mathers C, Parkin DM (2010) Estimates of worldwide burden of cancer in 2008: GLOBOCAN 2008. Int J Cancer 127(12):2893-2917

2. Piñeros M, Sánchez R, Cendales R, Perry F, Ocampo R (2009) Patient delay among Colombian women with breast cancer. Salud Publica Mex 51(5):372-380

3. Ceber E, Turk M, Ciceklioglu M (2010) The effects of an educational program on knowledge of breast cancer, early detection practices and health beliefs of nurses and midwives. J Clin Nurs 19: 2363-2371

4. Hackshaw AK, Paul EA (2003) Breast self-examination and death from breast cancer: a meta-analysis. Br J Cancer 88(7):1047-1053

5. American College of Obstetricians-Gynecologists (2011) Practice bulletin no. 122: breast cancer screening. Obstet Gynecol 8:373

6. Peacy V, Steptoe A, Davidsdóttir S, Baban A, Wardle J (2006) Low levels of breast cancer risk awareness in young women: an international survey. Eur J Cancer 42(15):2585-2589 
7. McMenamin M, Barry H, Lennon A (2005) A survey of breast cancer awareness and knowledge in a Western population: lots of light but little illumination. Eur J Cancer 41:393-397

8. Grunfeld E, Ramirez A, Hunter M, Richards M (2002) Women's knowledge and beliefs regarding breast cancer. Brit J Cancer 86 : 1373-1378

9. Waller J, McCaffery K, Wardle J (2004) Measuring cancer knowledge: comparing prompted and unprompted recall. Brit J Psychol 95:219-234

10. Mayor S (2016) Healthy lifestyle may reduce breast cancer in women at high risk, study shows. BMJ 353:i3047

11. Meneses-Echávez JF, Correa-Bautista JE, González-Jiménez E, Schmidt Río-Valle J, Elkins MR, Lobelo F, Ramírez-Vélez R (2016) The effect of exercise training on mediators of inflammation in breast cancer survivors: a systematic review with meta-analysis. Cancer Epidemiol Biomark Prev 25(7):1009-1017

12. Meneses-Echavez JF, González Jiménez E, Schmidt Río-Valle J, Correa-Bautista JE, Izquierdo M, Ramírez-Vélez R (2016) The insulin-like growth factor system is modulated by exercise in breast cancer survivors: a systematic review and meta-analysis. BMC Cancer 16:682

13. Golubnitschaja O, Debald M, Yeghiazaryan K, Kuhn W, Pešta M, Costigliola V, Grech G (2016) Breast cancer epidemic in the early twenty-first century: evaluation of risk factors, cumulative questionnaires and recommendations for preventive measures. Tumour Biol.

14. Colditz GA, Bohlke K (2014) Priorities for the primary prevention of breast cancer. CA Cancer J Clin 64(3):186-194

15. McTiernan A, Porter P, Potter JD (2008) Breast cancer prevention in countries with diverse resources. Cancer 113:2325-2330

16. Zeinomar N, Moslehi R (2013) The effectiveness of a communitybased breast cancer education intervention in the New York State Capital Region. J Cancer Educ 28(3):466-473

17. Akhtari-Zavare M, Juni MH, Said SM, Ismail IZ, Latiff LA, Ataollahi ES (2016) Result of randomized control trial to increase breast health awareness among young females in Malaysia. BMC Public Health 16:738

18. Santana-Chávez LA, Zepeda-FloreS SE, González-Muñoz LM, Meléndez-Morales J (2015) Effectiveness of supervised breast self-examination as educational strategy. Ginecol Obstet Mex 83(9):522-528

19. Kriemler S, Meyer U, Martin E, van Sluijs E, Andersen LB, Martin BW (2011) Effect of school-based interventions on physical activity and fitness in children and adolescents: a review of reviews and systematic update. $\mathrm{Br} \mathrm{J}$ Sports Med. 45(11): 10.1136/bjsports-2011-090186.

20. Pattraporn S, Warapone S, Mathuros T, Paranee V, Rachada K (2016) A cosmetic content-based nutrition education program improves fruit and vegetable consumption among grade 11 Thai students. J Nutr Educ Behav 48(3):190-198

21. Somsri 2016, Struempler BJ, Parmer SM, Mastropietro LM, Arsiwalla D, Bubb RR (2014) Changes in fruit and vegetable consumption of third-grade students in body quest: food of the warrior, a 17-class childhood obesity prevention program. J Nutr Educ Behav 46(4):286-292

22. Wiesner Ceballos C, Cortés García C, Donoso Suárez I. Guidelines for educational communication in the framework of cancer control. Bogotá; Instituto Nacional de Cancerología; 2008:46.

23. Ministerio de Salud y Protección Social - Instituto Nacional de Cancerología, ESE (2013) Plan Decenal para el Control del Cáncer en Colombia, 2012-2021. Bogotá, Colombia

24. Stubbings S, Robb K, Waller J, Ramirez A, Austoker J, Macleod U et al (2009) Development of a measurement tool to assess public awareness of cancer. Br J Cancer 101(2):13-17
25. Cancer Research UK [Internet] (2016) The Cancer Awareness Measures (CAM). London: Cancer Research UK; [cited 2016 Jul 22]. Available from: http://www.cancerresearchuk.org/healthprofessional/prevention-and-awareness/the-cancer-awarenessmeasures-cam

26. Pohls UG, Renner SP, Fasching PA (2004) Awareness of breast cancer incidence and risk factors among healthy women. Eur J Cancer Prev 13:249-256

27. Centers for Disease Control and Prevention (CDC). Behavioral Risk Factor Surveillance System Survey Questionnaire. Atlanta, Georgia: U.S. Department of Health and Human Services, Centers for Disease Control and Prevention.

28. Hacihasanoglu R, Gozum S (2008) The effect of training on the knowledge levels and beliefs regarding breast self-examination on women attending a public education centre. Eur J Oncol Nurs 12: 58-64

29. Haghighi F, Hoseini SM, Eshaghi S, Naseh GH, Tavakoli MR (2015) The effects of education on breast self-examination knowledge, attitude, and practice among the female employees of Birjand University. Mod Care J 12(1):47-53

30. Rezaeian M, Sharifirad GH, Mostafavi F, Moodi M, Abbasi MH (2014) The effects of breast cancer educational intervention on knowledge and health beliefs of women 40 years and older, Isfahan, Iran. J Edu Health Promot 3:59-64

31. Hanan M, Ola AA, Hala KI (2009) Impact of a health education intervention program about breast cancer among women in a semiurban area in Alexandria, Egypt. J Egypt Public Health Assoc 84(3\&2):219-243

32. Bala DV, Gameti H (2011) An educational intervention study of breast self examination (BSE) in 250 women beneficiaries of urban health centers of west Zone of Ahmedabad. Healthline 2(2):46-49

33. Sussman S, Dent CW, Stacy AW (2002) Project towards no drug abuse: a review of the findings and future directions. Am J Health Behav 26:354-365

34. Perry CL, Williams CL, Komro KA et al (2002) Project Northland: long-term outcomes of community action to reduce adolescent alcohol use. Health Educ Res 17:117-132

35. Strøm HK, Adolfsen F, Handegård BH, Natvig H, Eisemann M, Martinussen M, Koposov R (2015) Preventing alcohol use with a universal school-based intervention: results from an effectiveness study. BMC Public Health 15:337

36. Foxcroft DR, Tsertsvadze A (2011) Universal school-based prevention programs for alcohol misuse in young people. Cochrane Database Syst Rev 5:CD009113

37. Thomas RE, McLellan J, Perera R (2013) School-based programmes for preventing smoking. Cochrane Database of Systematic Reviews, Issue 4. Art. No.: CD001293. DOI: 10.1002/14651858.CD001293.pub3

38. U.S. Department of Health and Human Services (2012) Preventing tobacco use among youth and young adults: a report of the surgeon general. Atlanta, GA: U.S. Department of Health and Human Services, Centers for Disease Control and Prevention, National Center for Chronic Disease Prevention and Health Promotion, Office on Smoking and Health

39. Dobbins M, Husson H, DeCorby K, LaRocca RL (2013) Schoolbased physical activity programs for promoting physical activity and fitness in children and adolescents aged 6 to 18. Cochrane Database of Systematic Reviews. Issue 2. Art. No.: CD007651.

40. Evans CE, Christian MS, Cleghorn CL, Greenwood DC, Cade JE (2012) Systematic review and meta-analysis of school-based interventions to improve daily fruit and vegetable intake in children aged 5 to 12 y. Am J Clin Nutr 96(4):889-901 